\title{
Utilization of Municipal Plastic and Wood Waste in Industrial Manufacturing of Wood Plastic Composites
}

\author{
Dildare Basalp $^{1} \cdot$ Funda Tihminlioglu $^{1} \cdot$ Sait C. Sofuoglu ${ }^{2} \cdot$ Fikret Inal $^{1} \cdot$ Aysun Sofuoglu $^{1}$
}

Received: 20 September 2019 / Accepted: 23 February 2020 / Published online: 2 March 2020

(c) The Author(s) 2020

\begin{abstract}
In this study, Wood Plastic Composites (WPCs) were produced from post-consumer bulky wastes of recycled plastic and wood in order to minimize waste, decrease environmental effects of plastics, reserve natural resources, and support circular economy for sustainable production and consumption. Five different types of polypropylene (PP) or polyethylene (PE) based recycled plastics and wood obtained from urban household bulky wastes were used in the production of recycled WPC composites, r-WPCs. Virgin WPC (v-WPC) and r-WPC compounds were prepared with wood flour (WF) and maleic anhydride grafted compatibilizer (MAPP or MAPE) to evaluate the effect of recycled polymer type and compatibilizer on the mechanical properties. It was found that tensile strength properties of r-WPCs produced from recycled PP (r-PP) were higher than that of the r-WPCs produced from mixed polyolefins and recycled PE. r-WPCs containing anti-oxidants, UV stabilizers, and compatibilizer with different WF compositions were produced from only recycled garden fraction PP (PPFGF) to determine the optimum composition and processing temperature for pilot scale manufacturing of r-WPCs. Based on tensile, impact, flexural, and water sorption properties of r-WPC compounds with different formulations, the optimum conditions of r-WPC compounds for industrial manufacturing process were determined. Surface morphology of fractured surfaces as well as tensile, flexural and density results of r-WPC compounds revealed the enhancement effect of MAPP on interfacial adhesion in r-WPCs. r-WPC products (crates and table/chair legs) based on bulky wastes were produced using an injection molding process at industrial scale by using $30 \mathrm{wt} \%$ WF-filled r-WPC compound. This study demonstrated that r-WPC compounds from recycled bulky plastic and wood wastes can be used as a potential raw material in plastic as well as WPC industry, contributing to circular economy.
\end{abstract}

\section{Graphic Abstract}

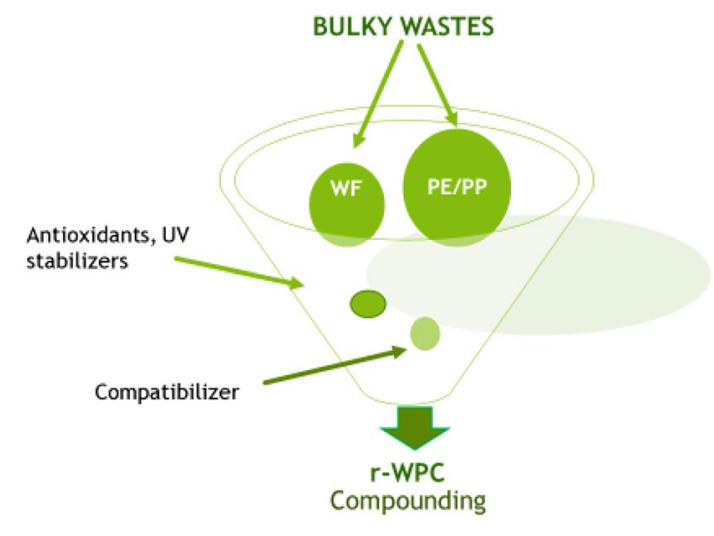

Keywords Wood plastic composite $\cdot$ Recycling $\cdot$ Bulky plastic waste $\cdot$ Mechanical property $\cdot$ WPC manufacturing

Extended author information available on the last page of the article 


\section{Statement of Novelty}

Bulky waste is a significant and increasing waste stream in every country due to change in habits and economic status resulting in finding affordable goods for the fast replacement. Municipal bulky waste stream could be treated as source if valorisation pathways have been studied. This study indicates valorisation of municipal plastics and wood waste as raw materials in WPC manufacture. The utilization of recyclable resources is imperative for sustainability, due to the increase in plastic waste in cities and the depletion of resources. In this concept, the evaluation of different types of plastics obtained from municipal bulky waste in WPC production were carried out by comparing the performance of the r-WPCs with virgin WPCs (v-WPC). Industrial manufacturing of r-WPC products from municipal bulky plastic and wood wastes was performed on pilot scale. Results indicate the technical feasibility of using bulky wastes as potential raw material for WPCs by considering physical and mechanical properties.

\section{Introduction}

The substitution of plastic by recycled post-consumer waste is very common around the globe due to the need for minimization of waste to reduce the environmental impact. Unfortunately, bulky waste is not utilized well for this purpose due to their large physical dimensions preventing collection along with domestic wastes, and requiring specific collection schemes. For example, the US Environmental Protection Agency (2006) [1] defined bulky waste as large items of waste materials, such as appliances, furniture, large auto parts, trees, stumps, wooden pallets, and waste tires. European Union summarizes bulky waste as the waste that needs special considerations for management due to their bulky character [2]. H2020 URBANREC project defines urban bulky waste as "mixed solid waste originating from the normal functioning of a private household and similar waste from companies that may require special collection and management because it cannot be accepted by the regular household waste collection systems due to its shape volume and/or weight". It includes, among others, furniture, mattresses, fixtures and fittings, upholstery and mixed textile, and large rigid plastic objects. Construction and demolition waste and any other bulky items for which specific waste management legislation at EU-level exists are excluded from the definition of urban bulky waste, e.g., packaging waste, waste electrical and electronic equipment (WEEE), end of life vehicles (ELV), and so forth [3]. The objective of the project is to valorise bulky waste with new innovative approaches, one of which is through wood-plastic composites.

It is estimated that approximately 19 million tonnes of furniture, mattresses, upholstery, textiles, and plastic garden products, among others in each year in the European countries end up in the waste, $60 \%$ of which goes to landfills [4]. Therefore, the plastic from bulky waste is a loss of an important resource that has a potential to be valorised, and to contribute to the circular economy and sustainability in accordance to the greening strategy in Europe [5]. Most of the plastic wastes are intrinsically non-biodegradable; therefore, their reutilization leads to the reduction of the environmental effects, dependency on petroleum resources, and promote ecosystems $[6,7]$. There are studies on the reusability of plastic wastes in various applications from production of fuel to cement, and wood-plastic composites (WPCs) [9-17]. Keskisaari and Karki [12] reported reduction in material costs with the use of waste materials, especially recycled plastic instead of virgin polymer in WPC.

WPC is defined as hybrid materials composed of wood flour (WF) and thermoplastic polymers. Wood as a fibrous filler material in WPC provides several advantages such as low cost, wood-like appearance, eco-friendly renewable filler, and reduction on the environmental effects of plastics [10-13, 18-21]. WPC combines the availability and aesthetic properties of wood, and moulding capability and high environmental resistance of plastics, such as against water [10, 18-23]. Moulding capability of plastics enhances the application areas of WPC at different shape profiles ranging from exterior and interior construction materials such as pallets, sidings, decks, and fences to automotive components such as seat backs and front/rear door linens [11,24-28].

The physical and mechanical properties of WPC are dependent on the wood content, polymer type, additives such as coupling agent or compatibilizer, and processing conditions. The compatibility between nonpolar polymer and polar wood in WPC is improved by surface modification of wood with coupling agent before WPC process or direct usage of compatibilizer such as maleic anhydride grafted polymer (MAPP or MAPE) during WPC process. The presence of polar and non-polar groups in the structure of coupling agents or compatibilizers provides the bonding between polymer and wood. This bond enhances the compatibility and the interfacial adhesion between polymer and wood, and leads to the improvement of mechanical properties of WPC [27-34].

There are few studies related to the mechanical properties of WPC from recycled polymer and wood. Bütün et al. [27] indicated the possibility of WPC production with recovered wood particles obtained from fibreboard (MDF) disintegration technique. Chaharmali et al. [35] produced WPC panels and particleboard with recycled HDPE bottles. Kamdel et al. [36] studied the mechanical properties of wood particles 
with recycled HDPE and compared with the virgin one. It was seen from these studies that mechanical properties of WPC from recycled polymer and wood, were comparable with the virgin ones. However, to our knowledge, there is no study related to the WPC production from bulky plastic and wood wastes.

The aim of this study is the use of plastics and wood obtained from municipal bulky waste for industrial manufacturing of WPC products that may be used in many diverse product applications. Consequently, waste minimization, reduction in environmental effects, protection of natural resources, and supporting circular economy for sustainable production and consumption could be realized. For the above mentioned aim, effect of wood content, plastic type, compatibilizer, and temperature on physical and mechanical properties of WPC in laboratory scale as well as later in industrial scale conditions were investigated. Furthermore, industrial pilot scale demonstration was performed with manufacturing two potential products.

\section{Materials and Methods}

Fractionated recycled polymers and wood waste obtained from urban bulky waste stream were supplied from Vanheede Environment Group (VEC) (Belgium), a partner of the URBANREC project. The plastics fraction consisted of polypropylene (PP) based garden furnitures and polyolefin (PO) based injection moulding waste products, were further treated in order to obtain plastic grades of higher quality. The treatment included size reduction, washing and flotation, removal of metal fractions, regrinding, and dedusting. The recycled polymers supplied from VEC tabulated in Table 1 were classified according to melt flow indexes (high, medium or low MFI), polymer type (PP, PE or mixed PO) and application area of recycled product (garden fraction (PPFGF) or artificial grass (LLDPEgrass). PPFGF consists of $10.7 \mathrm{wt} \%$ talc as a filler. Wood wastes from cases, pallets, etc., are collected, sorted, chopped, and ground down to
50-100 mesh size. Maleic anhydride grafted PP (Licocene PPMA 7452) and maleic anhydride grafted PE (Licocene 4351 PEMA) as compatibilizers were kindly supplied from Clariant Company (Germany). Virgin polypropylene (PP) and polyethylene (PE) based WPCs (v-WPC) were also prepared as a reference comparison. Virgin PP (MH 418) and virgin PE (I 668) were supplied from PETKIM petrochemical company (Turkey). MFI values of virgin PP and virgin $\mathrm{PE}$ are 4.5 and $5.5 \mathrm{~g} / 10 \mathrm{~min}$, respectively. Sonox 168 and Sonox 1010 supplied from Shandong Limyi Sunny Wealth were used as antioxidants. UV 70 (Sabo) and Plastaid-T (Fine Organics) were used as UV stabilizer and processing aid, respectively.

\section{Preparation of WPCs}

The steps of the plastic recycling and WPC production are given in Fig. 1. In the scope of this study, WPC production from recycled plastic and wood waste was carried out in both laboratory scale and industrial scale. Firstly, $50 \mathrm{wt} \% \mathrm{WF}$ filled WPCs composed of MAPP or MAPE were prepared in the laboratory scale for the selection of recycled polymer type. The recycled polymers and wood waste were dried at $90{ }^{\circ} \mathrm{C}$ before preparation of WPCs. WPC plates $(15 \times 15 \times 1$ $\mathrm{cm}$ ) in the laboratory scale were conducted by using Torque Rheometer (Thermo Haake Rheomixer) and then compression moulded in a hot press (Carver Press), successively. The PE or PP based WPCs were prepared at mixing temperature of 160 or $185{ }^{\circ} \mathrm{C}$, rotor speed of $40 \mathrm{rpm}$ and mixing time of $10 \mathrm{~min}$ in the torque rheometer. The specimens taken from the rheomixer were compression molded in a Carver press to form rectangular sheet with dimensions $150 \times 150 \times 1 \mathrm{~mm}^{3}$. Composites were pressed at 100 bar pressure at 185 or 200 ${ }^{\circ} \mathrm{C}$ for 8 minutes and then cooled to $40{ }^{\circ} \mathrm{C}$. Recycled PP and PE based thermoplastics polymers obtained from municipal waste were compounded with wood waste at various filler compositions (20-50 wt\%) and other additives (UV stabilizers, lubricant, and antioxidants, approximately 1.2 $\mathrm{wt} \%$ ) for determination of optimum WPC formulations in
Table 1 The properties of virgin and fractionated recycled polymers

\begin{tabular}{llll}
\hline $\begin{array}{l}\text { Sample } \\
\text { code }\end{array}$ & Polymer type & $\begin{array}{l}\text { Melting temperature } \\
\left(\mathrm{T}_{\mathrm{m}},{ }^{\circ} \mathrm{C}\right)\end{array}$ & $\begin{array}{l}\text { Melt flow index } \\
(\mathrm{MFI}) \text { at 230 }\end{array}$ \\
\hline $\mathrm{g} / \mathrm{C} / 10 \mathrm{~min})$
\end{tabular}




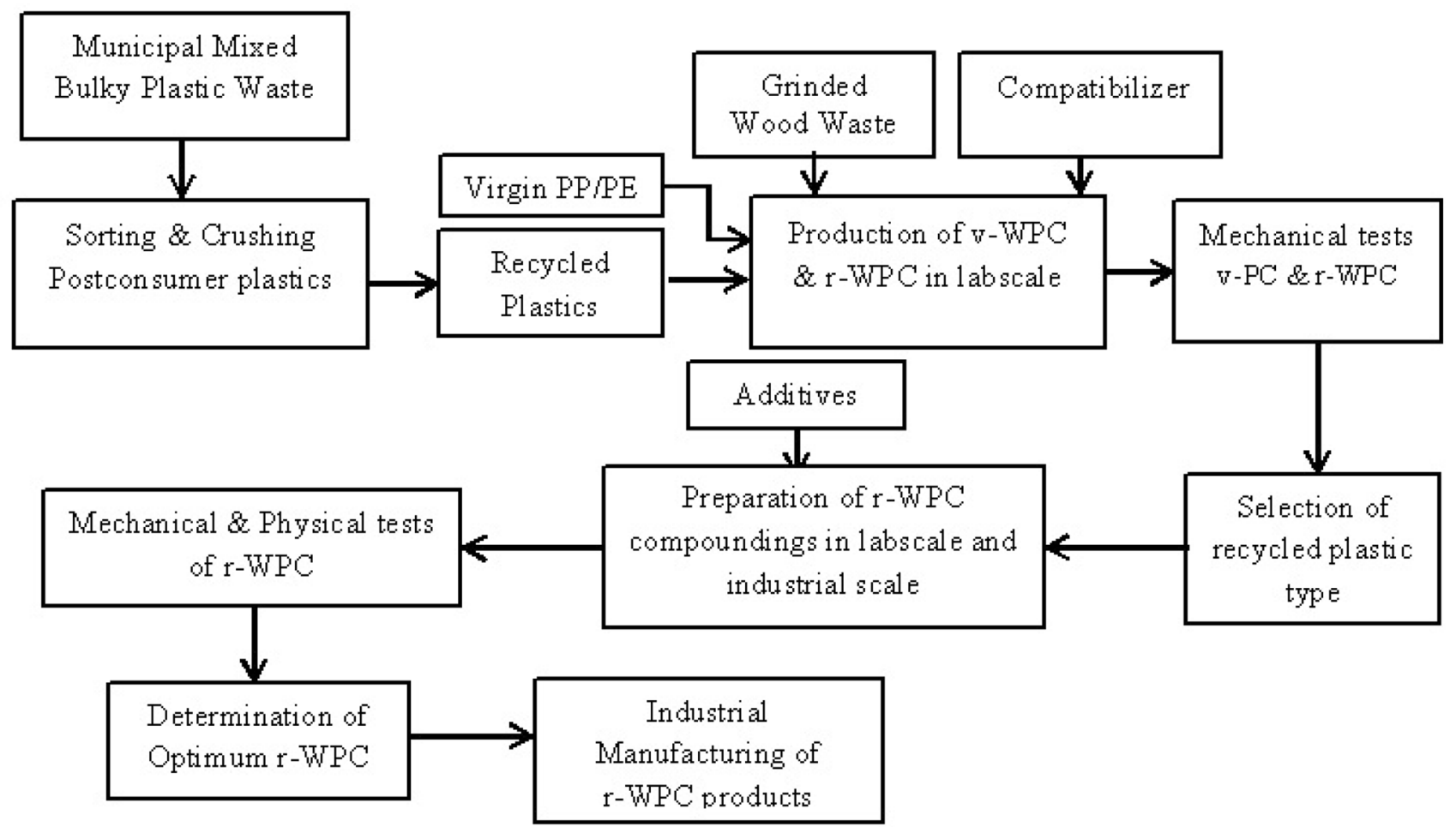

Fig. 1 WPC production steps

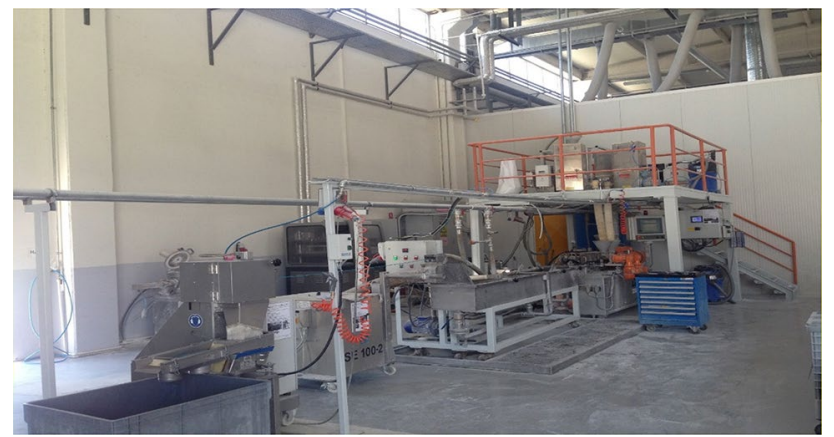

Fig. 2 Process line of industrial manufacturing of WPC compounds

the laboratory (Thermo Scientific PRISM EUROLAB 16) and industrial scale twin screw extrusion machines (Leistritz ZSE 27 MAXX).

Industrial scale WPC production of this study comprises the production of WPC compounds by twin screw extrusion first, and later manufacturing of WPC products by injection molding at industrial scale. The WPC compounds with optimized formulations were produced at different processing temperatures (Fig. 2). Processing parameters such as temperature profile through extrusion barrel to die, flow rate, and screw speed were adjusted for better flow properties. The maximum process temperature through industrial extrusion process was applied in the range of $185-215^{\circ} \mathrm{C}$.
At three different wood flour concentrations (20,30, and 40 wt\%), PPFGF compounds consisting all additives including UV stabilizer, antioxidants, compatibilizer, and lubricant were produced in a plastic compounding factory. WPC compounds were used for manufacturing of table legs and crates by using injection molding process (Haitian plastics machinery and Forstar Strong MCHX-220T) available in two different plastics companies.

\section{Tensile, Impact, and Flexural Tests of WPC Compounds}

Tensile, impact, flexural, and water sorption properties of WPC compounds with different formulations such as different wood flour content $(20,30,40 \mathrm{wt} \%)$, compatibilizer and other additives (UV, antioxidants) were investigated for the determination of optimum WPC compounds. The tensile tests of WPCs were carried out according to ASTM D638 standard in Shimadzu AG-I mechanical test equipment at a $10 \mathrm{~mm} / \mathrm{min}$ tensile test speed and $5 \mathrm{kN}$ load cell. The specimens were conditioned at $50 \%$ relative humidity for $24 \mathrm{~h}$ prior to testing. Among the five different fractionated recycled plastics, PPFGF was selected based on the tensile properties at constant WF loading (50 wt \%) for the industrial manufacturing of WPC compounds as well as WPC industrial product demonstrations. 
The notched Charpy Impact strength tests were conducted according to EN ISO 179-1 standard at room temperature by using a V-notch CEAST Resil Impactor. The test samples were prepared by using industrial injection molding process (Permak Injection Molding, TR) according to ISO 179-1 standard at $220{ }^{\circ} \mathrm{C}$ and 30 bar.

Three-point flexural bending tests of PP, PPFGF, and compounded PPFGFs composed of 20,30 and $40 \mathrm{wt} \%$ wood flour and other additives (antioxidants, UV stabilizer) were carried out for the determination of the flexural properties of the compounds. Test samples were prepared in injection molding equipment according to ASTM D 790-15 test method. Three-point flexural bending tests were performed by using AGS-J Shimadzu mechanical testing machine with $5 \mathrm{kN}$ load cell and support span length of $62 \mathrm{~mm}$. All mechanical test data described as an average of five test specimens with \pm standard error.

\section{Surface Morphology of WPC Compounds}

Morphological analyses of fractured surfaces of polymer composites can give us information about the interfacial interaction and the strength of adhesion between polymer matrix and filler. Surface morphology of tensile fracture section of WPCs were characterized by scanning electron microscope (FEI Quanta 250 FEG) to analyse the effects of the maleic anhydride grafted compatibilizer on the polymer/filler interface. The fractured surfaces of the tensile test specimens were sputter-coated with gold to avoid electron charging.

\section{Water Absorption and Density of WPC Compounds}

Water absorption (wt \%) and thickness swelling (\%) were determined by mass and thickness dimension measurement of WPC specimens according to Eq. (1). The dry WPC specimens with four replicates were immersed in water at room temperature for $24 \mathrm{~h}$. Then, the wet samples are removed and measured.

Water sorption $\%=\left(\left(W_{w}-W\right)_{d} / W_{d}\right) \times 100$

where $\mathrm{W}_{\mathrm{d}}$ and $\mathrm{W}_{\mathrm{w}}$ are the dry and wet mass of samples, respectively. Thickness swelling (\%) was also calculated using the same equation with thickness values instead of mass.

True density of WF was measured by using Helium pycnometer (Quantochrome Instruments, Ultrapycnometer 1000). Average theoretical density of WF with standard deviation was calculated by Software program "Pycwin Version 1.10 ". True density of WF was found as $1.5637 \pm 0.0024 \mathrm{~g} /$ $\mathrm{cm}^{3}$.
Densities of virgin PP, PPFGF and r-WPCs were measured by using the density determination kit Sartorius YDK 01 based on Archimedes principle. Weight of the sample in air $\left(\mathrm{W}_{\mathrm{a}}\right)$ and weight of the sample in ethanol $\left(\mathrm{W}_{\mathrm{e}}\right)$ were recorded to calculate experimental densities of the samples from the following equation.

$\rho_{\mathrm{s}}=\mathrm{W}_{\mathrm{a}} \times \rho_{\mathrm{e}} /\left(\mathrm{W}_{\mathrm{a}}-\mathrm{W}_{\mathrm{e}}\right)$

where $\rho_{\mathrm{s}}$ and $\rho_{\mathrm{e}}$ are densities of the sample and ethanol, respectively. Void fractions $(\varepsilon)$ of r-WPC compounds were calculated by considering experimental and theoretical densities $\left(\rho_{\text {theo }}\right)$ of r-WPC compounds. Theoretical densities and void fraction $(\varepsilon)$ of r-WPCs were calculated using Eqs. (3, 4).

$\rho_{\text {theo }}=\Sigma \mathrm{m}_{\mathrm{i}} / \sum\left(\mathrm{m}_{\mathrm{i}} / \rho_{\mathrm{i}}\right)$

$\rho_{\exp }=\rho_{\text {theo }}(1-\varepsilon)$

where $\mathrm{m}_{\mathrm{i}}$ and $\rho_{\mathrm{i}}$ represent the mass and density of component $i$ in the composite, respectively.

\section{Results and Discussion}

\section{Mechanical Properties}

Mechanical properties of recycled polymers depend on molecular weight, type and recycle rate of polymer, and processing conditions. The recycled polymers also consist of different type of fillers and additives. The type, shape, and amount of fillers and additives have an impact on mechanical properties of recycled polymers. Also, mixing of different type of incompatible polymers during recycle process adversely effects mechanical properties of the polymers. Fragmentation and classification of source of plastic waste play an important role for the quality and consistency of products produced from recycled polymers. The mechanical results of this study given below discusses the effects of the mentioned parameters on the mechanical as well as water sorption properties and density of the recycled WPCs, and compares with the virgin ones.

\section{Effects of Plastic Matrix and Compatibilizer on Tensile Strength (TS) and Modulus (E)}

Tensile properties of WPCs filled with $50 \mathrm{wt} \%$ wood flour were investigated firstly to decide the type of the recycled polymer for further industrial manufacturing of WPC compounds/products. Figure $3 \mathrm{a}, \mathrm{b}$ indicates the effects of compatibilizer and recycled polymer type on tensile strength and Young modulus values of WPCs at constant WF loading 

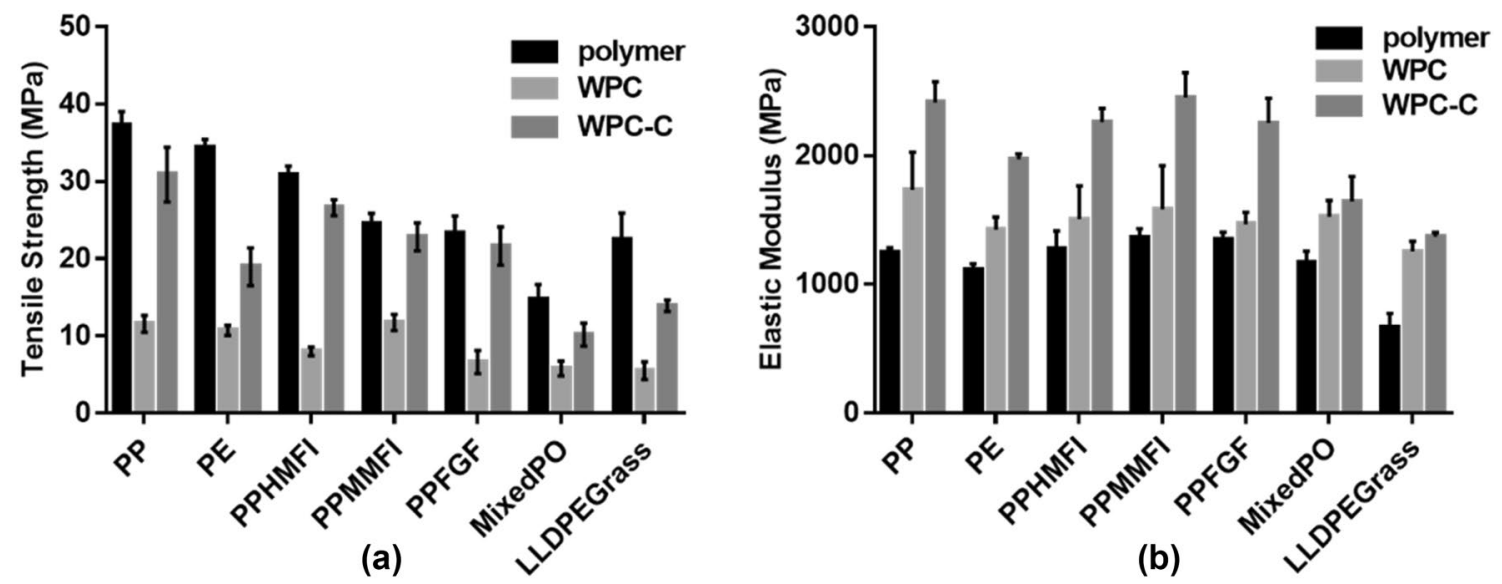

Fig. 3 Tensile properties of v-WPC and r-WPC

(50 wt\%), respectively, as well as compares the values with the virgin PP and PE polymers. As seen in the figure, tensile strength and Young modulus values of WPCs (WPCC) increased significantly with the use of MAPP or MAPE as compatibilizer. Tensile strengths of virgin PP and PE, found to be 37 and $34 \mathrm{MPa}$, respectively were higher than that of the recycled PPs and recycled PEs. However, tensile strength of virgin PP and PE significantly decreased with the addition of WF, and increased with the compatibilizer. At constant WF loading $50 \mathrm{wt} \%$, the tensile strength values of virgin PP, virgin PE, PPHMFI, PPMMFI, PPGF, MixPO, and LLDPE grass WPCs with MAPP or MAPE were found as $30.8,18.9,26.6,22.8,21.6,10.2$, and $13.8 \mathrm{MPa}$, respectively. The tensile strength values of WPCs produced from recycled MixPO and LLDPE found as $5.8 \mathrm{MPa}$ and $5.5 \mathrm{MPa}$ are the lowest tensile strength values compared to the other PP based recycled plastics and composites, respectively. Young modulus values calculated from the stress to strain ratio, that give information about the elastic deformation properties of the WPCs, ranged from 661 to $2530 \mathrm{MPa}$. The lowest Young modulus value was obtained in recycled LLDPE grass sample. The increase in Young modulus values indicates the increase of rigidity with the effect of WF and compatibilizer. Also, the increase in Young modulus values shows the increase in required stress for elastic deformation due to the increase of rigidity. The change of the strain at break values of virgin PP and PE also shows similar trend like tensile strength. Strain-at-break values of virgin PP, PE, and LLDPE grass significantly decreased with the addition of WF and increased with the compatibilizer. The highest strain-at-break value was found as $738 \%$ in recycled LLDPE grass sample. Strain-at-break values of WPCs were found to range between 1.3 and 3\%. Based on the tensile strength, Young modulus and strain-at-break data, it can be concluded that the use of compatibilizer led to improvement in the interfacial adhesion between WF and polymer. The improvement in mechanical properties of the composites with the use of compatibilizer were also reported by previous studies [27-34]. MAPP and MAPE provide a chemical bonding between the hydrophilic WF and hydrophobic polymer [23, 32, 34].

Among the five different fragmented bulky recycled plastics, polypropylene garden fractions (PPFGF) were used in the industrial manufacturing of WPC's based on the availability of these samples in the municipal waste stream, tensile mechanical properties, and melt flow behaviour. The medium MFI property of PPFGF as well as tensile strength were the critical factors in the selection of PPFGF for manufacturing process. MFI gives information about the resistance to flow of plastics during processing, and depends on the molecular weight and molecular weight distribution of the polymers. The polymers having low MFI value have high molecular weight, high melt viscosity, and long chains. The increase in MFI value with recycling of polymers was confirmed in previous studies [37]. In addition, the decrease in MFI value with the use of recycled plastics in many cycles was also determined due to the effect of additives and impurities present in recycled plastics. Haq and Srivastava [38] investigated the MFI, molecular weight, and crystalline behaviour of WPC produced by virgin and recycled PP. They found higher MFI value for virgin PP compared to recycled $\mathrm{PP}$ due to the effect of additives or impurities in recycled PP. MFI value decreased from 9.28 to 5.66 with an increase in WF content from 0 to $50 \%$ for recycled PP. This decrease in MFI with the increase in wood loading indicated the decrease in flowability of the composite material. In our study, based on the decrease in flowability of the plastics with wood content, PPFGF having medium MFI was selected. The use of PPFGF having medium MFI facilitated the processability with regard to melt flow behaviour through twin screw extrusion and injection molding 
machines. PPFGF having medium MFI provides the validation of WPCs for different applications as a processing point of view.

\section{Effect of WF Content on the Mechanical and Physical Properties of Industrial WPC Compounds}

WPC compounds were produced by using recycled PPFGF, $\mathrm{WF}$ waste (in varying amount of 20, 30 and $40 \mathrm{wt} \%$ ), MAPP (3 wt \%), and other additives such as antioxidants, UV stabilizer, and lubricant (approximately 1-2 wt\%) in industrial scale at two different temperatures $\left(185\right.$ and $215^{\circ} \mathrm{C}$ ) as decided based on prelimary laboratory scale studies. Caceres et. al [39] studied the chain scission PP degradation during multiple extrusions. Epacher et al. [40] and Santoz et al. [41] indicated the positive effects of Irganox 1010 and Irganox 168 as antioxidants for stabilization of HDPE and $\mathrm{PP} / \mathrm{PE}$ polyolefins during multiple extrusions by considering degradation. Based on the previous studies, additives were also used for heat stabilization of recycled PPFGF by preventing its degradation during the production of r-WPC compounds. The effect of WF content and compatibilizer on the tensile, impact, flexural, and water sorption properties on WPC compounds were investigated for the selection of r-WPC compounding with optimum formulation.

\section{Tensile Properties}

Tensile tests of the r-WPC compounds were carried out in order to define the optimum WF content and process temperature in industrial scale fabrication of WPC compounds. Figure $4 a, b$ depicts the tensile strength and elastic modulus data as a function of WF loading. As seen in Fig. 4a, tensile strength values of the WPC compounds decrease with the increase of process temperature and wood flour loading except $30 \mathrm{wt} \% \mathrm{WF}$. As expected, the higher process temperature decreased the melt viscosity, however, the state of polymer melts not only depend on temperature, but also shear forces in the melt. Therefore, it can be said that the higher shear forces exist in the melt at the lower process temperature that resulted in higher tensile strength and modulus values. The maximum tensile strength value was obtained as $24.8 \mathrm{MPa}$ in the $30 \mathrm{wt} \% \mathrm{WF}-$ filled WPC compounds processed at the lower process temperature $\left(185^{\circ} \mathrm{C}\right)$. The minimum tensile strength value was determined in the $40 \mathrm{wt} \%$ highest WF-filled WPC compounding processed at $215^{\circ} \mathrm{C}$. The tensile strength of $30 \mathrm{wt} \%$ WF-filled industrial r-WPC compounds (24.8 MPa) was found to be higher than that of $50 \mathrm{wt} \%$-WF filled lab scale r-WPC compounds (21.6 MPa). The increase in elastic modulus values of r-WPC obtained in industrial scale was observed with the increase of WF content and decrease of processing temperature (Fig. 4b). Therefore, the optimum process temperature for industrial extrusion process was determined as $185^{\circ} \mathrm{C}$ for further industrial WPC product manufacturing.

\section{Impact Properties}

Impact testing of virgin PP, recycled garden fraction PP (PPFGF), and $\mathrm{r}-\mathrm{WPC}$ compounds were carried out for determination of the effects of recycling and WF content on the impact test strength results. Figure 5 illustrates the impact strengths of notched virgin PP, recycled PPFGF, and WPC compounds filled with 20,30 and $40 \mathrm{wt} \% \mathrm{WF}$ (20 WF, $30 \mathrm{WF}$, and $40 \mathrm{WF}$ ) samples. The virgin PP has a higher impact strength found to be $10.5 \mathrm{~kJ} / \mathrm{m}^{2}$ compared to that of the r- PPFGF and r-WPC compounds. The result from the Charpy impact test of notched specimens indicates that impact strength significantly decreases with the use of recycled polymer and WF. The decrease in impact strength with recycling of PP indicates the PP embrittlement [42]. The decrease in impact strength with recycling and WF loading also reveals the reduction of adsorbed energy by breaking the specimens during impact test. The addition

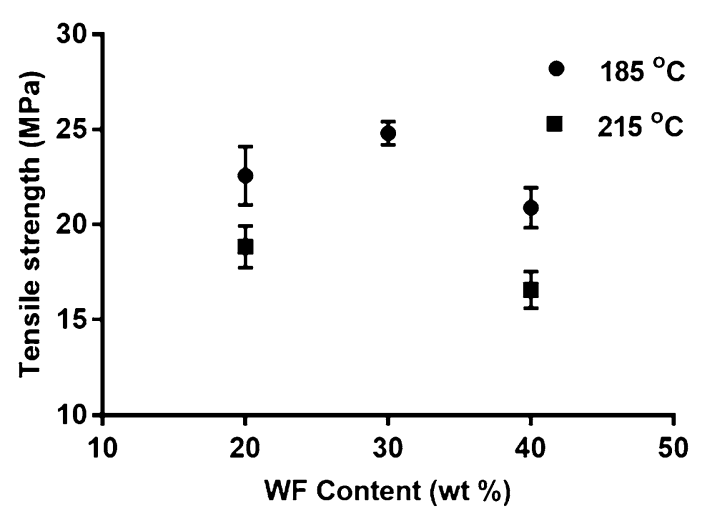

(a)

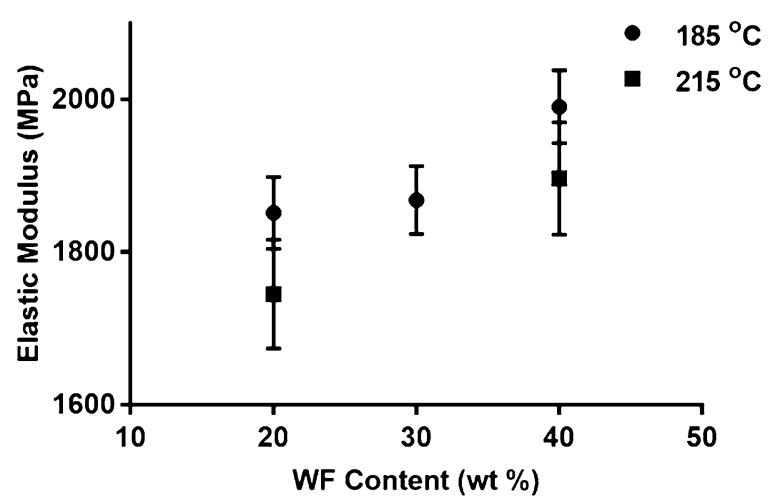

(b)

Fig. 4 Tensile properties of r-WPC compounds extruded at 185 and $215^{\circ} \mathrm{C}$ : a Tensile Strength $\mathbf{b}$ Elastic Modulus 


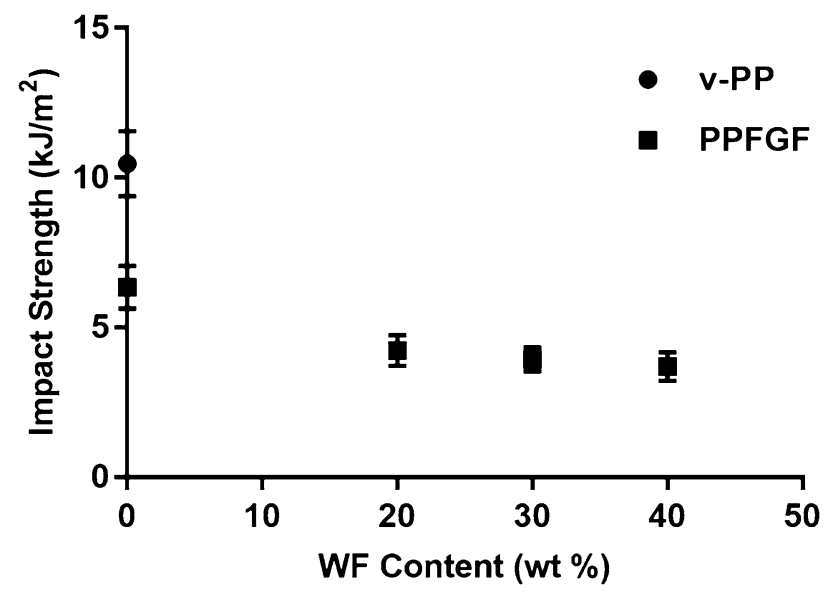

Fig. 5 Impact strengths of notched PP and PPFGF based r-WPC compounds at different WF loadings

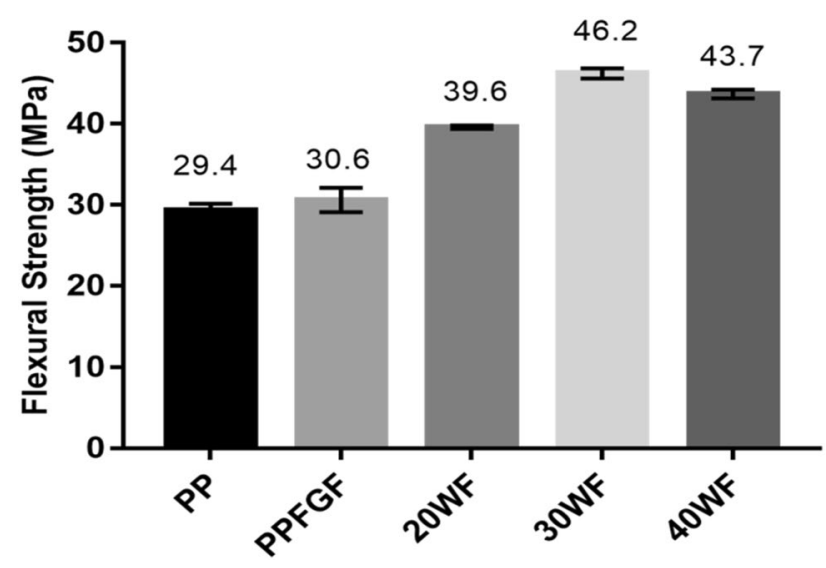

Fig. 6 Flexural strengths of PP, PPFGF, and r-WPC compounds at different WF loadings

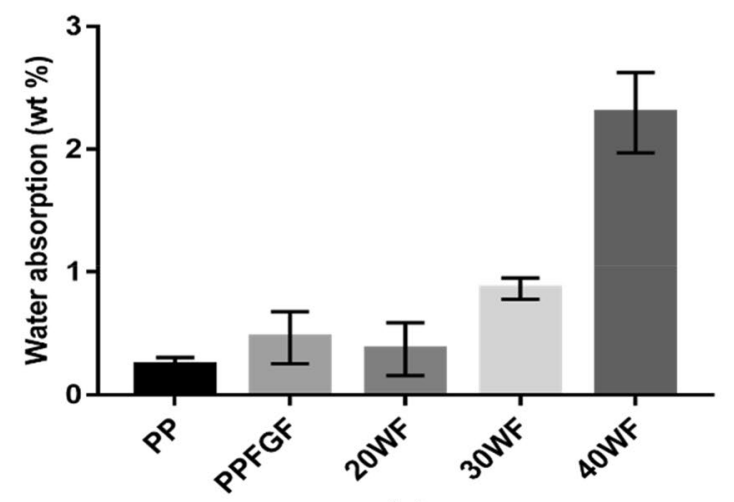

(a) of WF increased stiffness and brittleness of WPCs due to the decrease of flexibility of r-PP. However, no significant change was observed through impact test results of WPC compounds with an increase in WF loading approximately found as $4 \mathrm{~kJ} / \mathrm{m}^{2}$.

\section{Flexural Properties}

Three-point flexural bending tests of PP, PPFGF, and compounded PPFGFs composed of 20, 30, and 40 wt \% WF with other additives (antioxidants, UV stabilizer) were carried out for determination of the flexural properties.. The flexural strength values are given in Fig. 6. The flexural strength values were significantly increased with the addition of WF and MAPP in all PPFGF compounds (Fig. 6). It was found that the lowest flexural strength was in virgin PP. The maximum flexural strength, determined in Fig. 6 as 46.2 MPa, was obtained for $30 \mathrm{wt} \% \mathrm{WF}$-filled PPFGF compounds as seen in Fig. 6. The increase in flexural strength with MAPP could be attributed to the improvement on interfacial adhesion between WF and recycled PPFGF due to the possible bonding between WF and r-PP matrix, and improved dispersion of WF particles. The esterification reaction between anhydride carbonyl groups of MAPP and hydroxyl groups of the WF can lead to the formation of ester bonds. The increase in flexural strength with MAPP was observed similar to the tensile test results of WPC compounds. The positive effect of MAPP on tensile and flexural properties was also reported in previous studies about WPC composites [31, 38].

\section{Water Absorption, Swelling and Density Properties}

Water absorption and swelling properties of WPC composites play an important role in the determination of WPC applications. Figure 7a, b depicts the water absorption and swelling results of virgin PP, PPFGF, and r-WPC compounds at different WF loadings calculated from Eq.

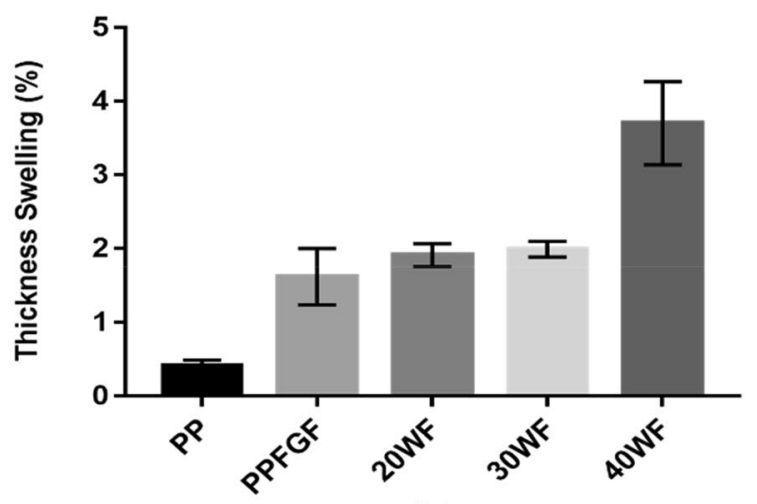

(b)

Fig. 7 a Water absorption and $\mathbf{b}$ Swelling results of virgin PP, PPFGF, and r-WPC compounds at different WF loadings 
(1). The water absorption was increased with the incorporation of WF. Considerable difference was not observed up to $20 \mathrm{wt} \% \mathrm{WF}$, however the water sorption increased significantly for 30 and $40 \mathrm{wt} \%$ WPCs. The water absorption of PPFGF was found to be higher than that of the virgin PP. This can be explained by the presence of 10.7 wt\% talc content in PPFGF as a filler. Water absorption results of r-WPC compounds except $40 \mathrm{wt} \%$ WF-filled WPC compound were found to be lower than $1 \mathrm{wt} \%$. Also, $\%$ thickness swelling results were lower than $2 \%$ except $40 \mathrm{wt} \%$ WF-filled WPC compound. Dimensional stability of WPC across water determines the suitability of WPC for outdoor applications. The water absorption $<1 \mathrm{wt} \%$ is recommended for many WPC market applications [43]. Based on the water absorption and swelling results, it can be contemplated that $\mathrm{r}$-WPC compounds consisting 20 and $30 \mathrm{wt} \% \mathrm{WF}$ are suitable for WPC applications.

Figure 8a illustrates the experimental and theoretical densities of r-WPC containing $50 \mathrm{wt} \% \mathrm{WF}$ without compatibilizer and r-WPC compounds with compatibilizer at different WF loadings. Theoretical densities of WF filled WPCs were found as higher than that of the experimental densities. Theoretical densities were obtained in the range of 1.08 and $1.22 \mathrm{~g} / \mathrm{cm}^{3}$. Experimental densities of 20,30, 40 and 50 wt $\%$ WF filled r-WPCs were found as 1.06, 1.1, 1.13 and $1.11 \mathrm{~g} / \mathrm{cm}^{3}$, respectively. The linear increase in experimental densities was observed with the increase of WF loading except for r-WPCs without MAPP, and good agreement with the literature [43]. The difference between theoretical and experimental densities of WPCs indicates the presence of voids. The effects of WF loading on void fractions of r-WPC compounds are shown in Fig. 8b. Void fractions of r-WPC compounds increase with WF loading. The void fractions of 20, 30 and $40 \mathrm{wt} \% \mathrm{r}$-WPCs were obtained as $0.024,0.019$ and 0.035 , respectively. The maximum void fraction value was obtained as 0.093 for $50 \mathrm{wt} \%$ WF filled WPC without MAPP due to the insufficient adhesion between polymer matrix and WF. Water sorption properties of WPCs directly depend on the void fractions. The void fraction results verify the increase in water sorption with WF loading.

\section{Characterization of Fracture Surfaces}

Micro-structural analysis of fractured surfaces of tensile test specimens were carried out to examine the adhesion between filler and polymer matrix, and dispersion of fillers. Figure 9 shows the fractured surfaces of tensile test samples of $30 \mathrm{wt} \%$ WF-filled r-WPC with and without MAPP. The holes and debonded WF fibers are clearly observed in r-WPC without compatibilizer. The observation of holes and the pulled out WF fibers confirms the weak interfacial adhesion between WF and polymer matrix in r-WPC without MAPP. The presence of weak interfacial adhesion between WF and polymer leads to the debonding of WF fiber from the polymer matrix easily during the tensile test. This result also confirms the reduction in the tensile mechanical strength of the r-WPCs without MAPP. The SEM micrograph in Fig. 9b indicated that the WF is dispersed well, and impregnated with the polymer matrix in r-WPC with MAPP. The decrease in number of cavities and gaps was observed in $30 \mathrm{wt} \% \mathrm{WF}-$ filled WPC with MAPP. As seen in Fig. 9c at higher magnification, SEM micrographs demonstrate the strong bonding between WF and matrix due to the absence of holes and the impregnation of WF fibers with the polymer matrix (Fig. 9b, c). SEM analyses supported the improvement effect of MAPP on interfacial adhesion between hydrophilic WF and PPFGF matrix. This result also confirms the improvement effects of MAPP on the tensile mechanical properties of WPCs due to the increase in stress transfer.
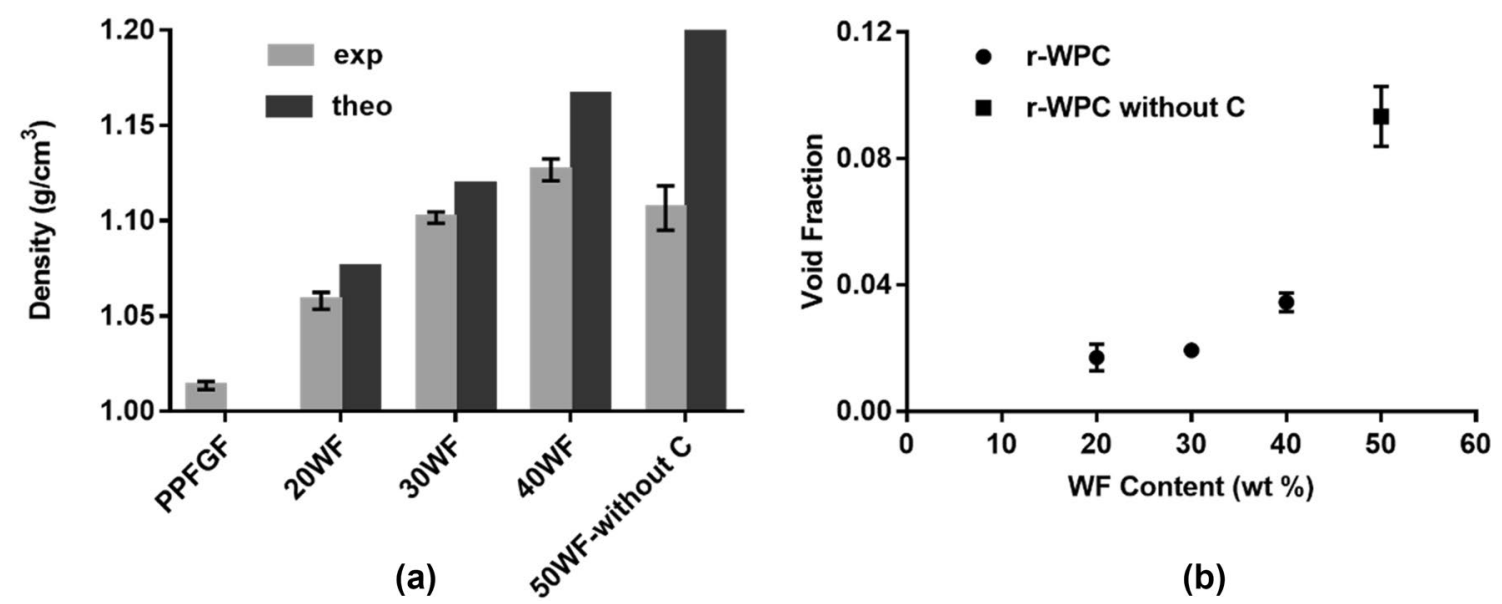

\section{(b)}

Fig. 8 a Experimental and theoretical densities, b Void fractions of r-WPC compounds at different WF loadings 


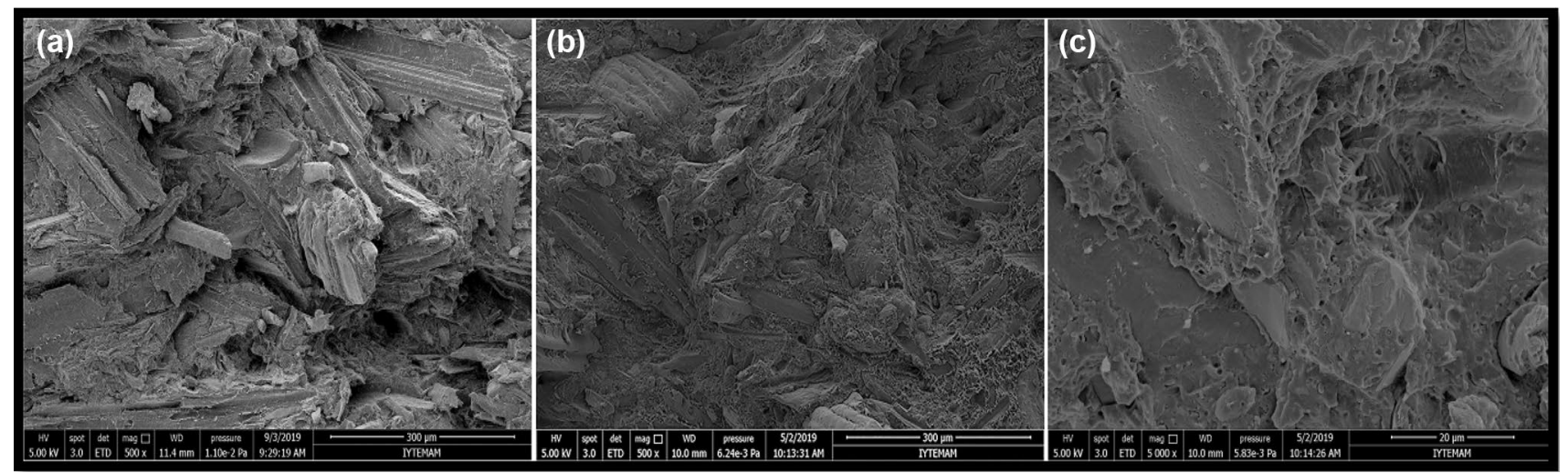

Fig. 9 SEM Micrographs of tensile fracture section of $30 \mathrm{wt} \%$ WF-filled a r-WPC without MAPP $\times 500 \mathbf{b}$ r-WPC with MAPP $\times 500$, and $\mathbf{c}$ r-WPC with MAPP $\times 5000$

\section{Industrial Manufacturing of WPC Products}

The WPC compounds with optimum formulations were used in industrial manufacturing process line by considering water absorption and mechanical properties. Table/chair legs and crates as potential products were manufactured by using injection molding equipment available in industrial plastic companies as shown in Fig. 10. The usage of recycled plastics and wood in the industrial manufacturing also leads to reduction on the melting temperature resulting in lower process temperature, lower energy consumption, and cost savings for producers [44]. Industrial manufacturing of WPCs from bulky waste leads to decrease in manufacturing cost due to the decrease in material costs as well as the reduction of the environmental effects of plastic waste.

Manufacturing of crates and table legs indicates the applicability of WPCs from recycled plastics in transport of packed food products or vegetables/fruits and furniture sector, respectively. Also, many alternative WPC products depending on the consumer needs could be produced from bulky recycle plastics and woods.

\section{Conclusions}

In this study, the utilization of municipal bulky plastic and wood wastes was investigated for the industrial manufacturing of potential wood plastic composite (WPC) products. Successful substitutions of recycled bulky plastic and wood wastes with the virgin ones have been demonstrated. The optimum r-WPC formulations and processing temperature were determined by comparing the tensile, impact, and flexural mechanical tests results. The increase in processing temperature from 185 to $215{ }^{\circ} \mathrm{C}$ adversely affected the
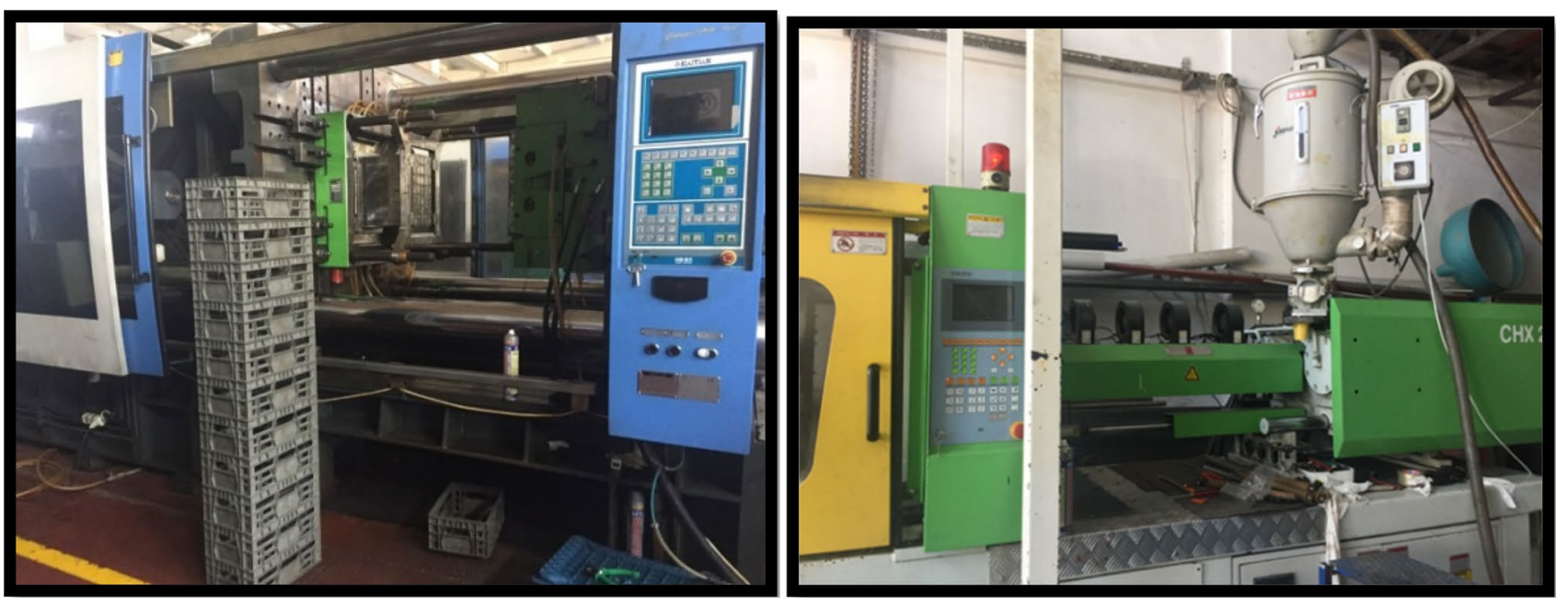

Fig. 10 Industrial manufacturing of crates and table legs from WPC compounds by using injection molding process 
tensile properties of the WPC compounds. The increase in tensile and flexural, and the decrease in water sorption properties and void fractions of the WPC composites with MAPP indicate the enhancement of the interfacial adhesion between wood flour (WF) and recycled PPFGF in WPC. The maximum improvement on mechanical and physical properties was obtained for WF-filled WPCs produced at $185^{\circ} \mathrm{C}$. In addition, $30 \mathrm{wt} \% \mathrm{WF}$ containing WPCs as the optimum WPC composition was used for industrial WPC manufacturing trials by considering the required mechanical and physical properties. Industrial manufacturing of two potential WPC products (table/chair legs and crates) for two different applications was demonstrated with the optimum material formulation with injection molding process. Manufacturing of crates and table legs showed successful substitutions of recycled bulky plastics and wood wastes with the virgin ones, and therefore, in order to contribute to the circular economy, valorisation of these wastes by upscaling laboratory results for development of marketable new products need to be explored.

Acknowledgements URBANREC project has received funding from the European Union's Horizon 2020 Research and Innovation Programme under Grant Agreement No 690103. The authors would like to thank Vanheede Environmental Group for fragmented recycled polymer and wood wastes. Centre for Materials Research of İzmir Institute of Technology (MAM) is acknowledged for tensile testing and SEM measurements.

Open Access This article is licensed under a Creative Commons Attribution 4.0 International License, which permits use, sharing, adaptation, distribution and reproduction in any medium or format, as long as you give appropriate credit to the original author(s) and the source, provide a link to the Creative Commons licence, and indicate if changes were made. The images or other third party material in this article are included in the article's Creative Commons licence, unless indicated otherwise in a credit line to the material. If material is not included in the article's Creative Commons licence and your intended use is not permitted by statutory regulation or exceeds the permitted use, you will need to obtain permission directly from the copyright holder. To view a copy of this licence, visit http://creativecommons.org/licenses/by/4.0/.

\section{References}

1. Environmental Protection Agency, 2006. Terms of environment: glossary, abbreviations and acronyms. https://iaspub.epa.gov/ sor_internet/registry/termreg/searchandretrieve/termsandacronym s/search.do (2006)

2. European Commission: Eurostat: Unit E2 - Environmental statistics and accounts; sustainable development Guidance on municipal waste data collection May 2017. https://ec.europa.eu/eurostat/ documents/342366/351811/Municipal+Waste+guidance+docum ent/bd38a449-7d30-44b6-a39f-8a20a9e67af. Accessed 4 Sept 2019

3. Handbook on the Implementation of EC Environmental Legislation: https://ec.europa.eu/environment/archives/enlarg/handbook/ waste.pdf
4. Crespo, A.I., Raquel, G., Pérez, V.E., M.: URBANREC: New approaches for the valorisation of URBAN bulky waste into high added value RECycled products, 11th Conference on Sustainable Development of Energy, Water and Environment System, 2016

5. Malinauskaite, J., Jouhara, H., Czajczynska, D., Stanchev, P., Katsou, E., Rostkowski, P., Thorne, R.J., Colon, J., Ponsa, S., Al-Mansour, F., Anguilano, L., Krzyzynska, R., Lopez, I.C., Vlasopoulos, A., Spencer, N.: Municipal solid waste management and waste-to-energy in the context of a circular economy and energy recycling in Europe. Energy 141, 2013-2044 (2017)

6. Goswami, U., Sarma, H.P.: Plastic waste pollution and management-an overview (Review). Ecol. Environ. Conserv. 14(1), 25-28 (2008)

7. Hopewell, J., Dvorakand, R., Kosior, E.: Review plastics recycling: challenges and opportunities. Philos. Trans. R. Soc. B 364, 2115-2126 (2009)

8. Kunwar, B., Cheng, H.N., Chandrashekaran, S.R., Sharma, B.K.: Plastics to fuel: a review. Renew. Sustain. Energy Rev. 54, 421428 (2016)

9. Sharma, R., Bansal, P.P.: Use of different forms of waste plastic in concrete-a review. J. Clean. Prod. 112, 473-482 (2016)

10. Turku, I., Keskisaari, A., Karki, T., Puurtinen, A., Marttila, P.: Characterization of wood plastic composites manufactured from recycled plastic blends. Compos. Struct. 161, 469-476 (2017)

11. Teuber, L., Osburg, V., Toporowski, W., Militz, H., Krause, A.: Wood polymer composites and their contribution to cascading utilisation. J. Clean. Prod. 110, 9-15 (2016)

12. Keskisaari, A., Karki, T.: The use of waste materials in woodplastic composites and their impact on the profitability of the product. Resources Conserv. Recycl. 134, 257-261 (2018)

13. Najafi, S.K.: Use of recycled plastics in wood plastic composites-a review. Waste Manag. 33, 1896-1905 (2013)

14. Sommerhuber, P., Wang, T., Krause, A.: Wood-plastic composites as potential applications of recycled plastics of electronic waste and recycled particleboard. J. Clean. Prod. 121, 176-185 (2016)

15. Sommerhuber, P., Welling, J., Krause, A.: Substitution potentials of recycled HDPE and wood particles from post-consumer packaging waste in wood-plastic composites. Waste Manag. 46, 76-85 (2015)

16. Dayana, S., Sharuddin, A., Abnisa, F., Mohd, W., Daud, A.W., Aroua, M.K.: A review on pyrolysis of plastic wastes. Energy Conserv. Manag. 115, 308-326 (2016)

17. Al-Salem, S.M., Lettieri, P., Baeyens, J.: The valorization of plastic solid waste (PSW) by primary to quaternary routes: From reuse to energy and chemicals. Progr. Energy Combust. Sci. 36(1), 103-129 (2010)

18. Ratanawilai, T., Taneerat, K.: Alternative polymeric matrices for wood-plastic composites: Effects on mechanical properties and resistance to natural wheathering. Construct. Build. Mater. 127, 349-357 (2018)

19. Leu, S.Y., Yang, T.H., Lo, S.P., Yang, T.H.: Optimized material composition to improve the physical and mechanical properties of extruded wood-plastic composites (WPCs). Construct Build. Mater. 29, 120-127 (2012)

20. Schwarzkopf, M.J., Burnard, M.D.: Wood-plastic compositesPerformance and environmental impacts. In: Kutnar, A., Muthu, S. (eds.) Environmental Impacts of Traditional Andi Innovative Forest-Based Bioproducts Environmental Footprints and EcoDesign of Products and Processes. Springer, Singapore (2016)

21. Kumar, V., Tyagi, L., Sinha, S.: Wood flour-reinforced plastic composites: a review. Rev. Chem. Eng. 27(5-6), 253-264 (2011)

22. Koivuranta, E., Hietala, M., Ammala, A., Oksman, K., Illikinen, M.: Improved durability of lignocellulose-polypropylene composites manufactured using twin-screw extrusion. Compos. A 101, 265-272 (2017) 
23. Yang, H.S., Kim, H.S., Park, H.J., Lee, B.J., Hwang, T.S.: Water absorption behaviour and mechanical properties of lignocellulosic filler-polyolefin bio-composites. Compos. Struct. 72, 429-437 (2006)

24. Smith, P.M., Wolcott, M.P.: Opportunities for wood/natural fiberplastic composites in residential and industrial applications. Forest Prod. J. 56(3), 4-11 (2006)

25. Venkatesh, G.S., Deb, A., Karmarkar, A., Gurumoorthy, B.: EcoFriendly Wood polymer composites for sustainable design applications. In: Chakrabarti, A. (ed.) CIRP Design 2012. Springer, London (2013)

26. Chaharmahali, M., Mirbagheri, J., Tajvidi, M., Najafi, S.K., Mirbagheri, Y.: Mechanical and physical properties of wood-plastic composite panels. J. Reinf. Plast. Compos. 29(2), 310-319 (2010)

27. Bütün, F.Y., Sauerbier, P., Militz, H., Mai, H.: The effect of fibreboard (MDF) disintegration technique on wood polymer composites (WPC) produced with recovered wood particles. Compos. A. 118, 312-316 (2019)

28. Ashori, A.: Wood-plastic composites as promising green-composites for automotive industries! Biores. Technol. 99(11), 46614667 (2008)

29. Sohn, J.S., Cha, S.W.: Effect of chemical modification on mechanical properties of wood-plastic composite injection molded parts. Polymers 10(1391), 1-13 (2018)

30. Huang, C.W, Yang, T.C., Wu, T.L., Hung, K.C.: Effects of maleated polypropylene content on the extended creep behavior of wood-polypropylene composites using the stepped isothermal method and the stepped isostress method. Wood Sci. Technol. 52(5), 313-330 (2018)

31. Bhaskar, J., Haq, S., Yadaw, S.B.: Evaluation and testing of mechanical properties of wood plastic composite. J. Thermoplast. Compos. Mater. 25(4), 391-401 (2011)

32. Kim, H.S., Lee, B.H., Choi, S.W., Kim, S., Kim, H.J.: The effect of types of maleic anhydride-grafted polypropylene (MAPP) on the interfacial adhesion properties of bio-flour filled polypropylene composites. Compos. A 38, 1473-1482 (2007)

33. Zhou, Y., Fan, M., Lin, L.: Investigation of bulk and in situ mechanical properties of coupling agents treated wood plastic composites. Polym. Test. 58, 292-299 (2017)

34. Nidiaye, D., Matuana, L.M., Morlat-Therias, S., Vidal, 1, Tidjani, A., Gardette, J.L.: Thermal and mechanical properties of polypropylene/wood-flour composites. J. Appl. Polym. Sci. 119(6), 3321-3328 (2011)

\section{Affiliations}

\section{Dildare Basalp $^{1} \cdot$ Funda Tihminlioglu ${ }^{1} \cdot$ Sait C. Sofuoglu ${ }^{2} \cdot$ Fikret Inal $^{1} \cdot$ Aysun Sofuoglu $^{1}$}

Funda Tihminlioglu

fundatihminlioglu@iyte.edu.tr

Aysun Sofuoglu

aysunsofuoglu@iyte.edu.tr
35. Chaharmahali, M., Tajvidi, M., Kazemi-Najafi, S.: Mechanical properties of wood plastic composite panels made from waste fibreboard and particleboard. Polym. Compos. 29(6), 606-610 (2008)

36. Kamdem, P., Jiang, H., Cui, W., Freed, J., Matuana, L.M.: Properties of wood plastic composites made of recycled HDPE and wood flour from CCA treated wood removed from service. Compos. Appl. Sci. Manuf. 35(3), 347-355 (2004)

37. Hinsken, H., Moss, S., Pauqueta, J.R., Zweifel, H.: Degradation of polyolefins during melt processing. Polym. Degrad. Stabil. 34(1-3), 279-293 (1991)

38. Haq, S., Srivastava, R.: Wood polypropylene (PP) composites manufactured by mango wood waste with virgin or recycled PP: mechanical, morphology, Melt Flow Index and crystalline Behaviour. J. Polym. Environ. 25, 640-648 (2017)

39. Caceres, C.A., Zborowski, L., Canevarolo, S.V.: Thermo-mechanical degradation and VOC emission of unstabilized and stabilized polypropylene copolymer during multiple extrusions. Mater. Res. 14(4), 569-575 (2011)

40. Epacher, E., Tolveth, J., Stoll, K., Pukanszky, B.: Two-step degradation of high-density polyethylene during multiple extrusion. J. Appl. Polym. Sci. 74, 1596-1605 (1999)

41. Santos, A.S.F., Agnelli, J.A.M., Trevisan, D.W., Manrich, S.: Degradation and stabilization of polyolefins from municipal plastic waste during multiple extrusions under different reprocessing conditions. Polym. Degrad. Stabil. 77, 441-447 (2002)

42. Barbosa, L.G., Piaia, M., Ceni, G.H.: Analysis of impact and tensile properties of recycled polypropylene. Int. J. Mater. Eng. 7(6), 117-120 (2017)

43. Klyosov, A.: Wood Plastic Composites. Wiley Interscience, Hoboken, New York (2007)

44. Aurrekoetxea, J., Sarrionandia, M.A., Urrutibeascoa, I., Maspoch, M.L.: Effects of recycling on the microstructure and the mechanical properties of isotactic polypropylene. J. Mater. Sci. 36, $2607-$ $2613(2001)$

Publisher's Note Springer Nature remains neutral with regard to jurisdictional claims in published maps and institutional affiliations. 